\title{
Development and validation of a clinical prediction rule for chest wall syndrome in primary care
}

Alexandre Ronga ${ }^{1 *}$, Paul Vaucher ${ }^{1,2}$, Jörg Haasenritter ${ }^{3}$, Norbert Donner-Banzhoff $^{3}$, Stefan Bösner ${ }^{3}$, François Verdon", Thomas Bischoff', Bernard Burnand ${ }^{4}$, Bernard Favrat ${ }^{5}$ and Lilli Herzig ${ }^{1}$

\begin{abstract}
Background: Chest wall syndrome (CWS), the main cause of chest pain in primary care practice, is most often an exclusion diagnosis. We developed and evaluated a clinical prediction rule for CWS.

Methods: Data from a multicenter clinical cohort of consecutive primary care patients with chest pain were used (59 general practitioners, 672 patients). A final diagnosis was determined after 12 months of follow-up. We used the literature and bivariate analyses to identify candidate predictors, and multivariate logistic regression was used to develop a clinical prediction rule for CWS. We used data from a German cohort $(n=1212)$ for external validation.

Results: From bivariate analyses, we identified six variables characterizing CWS: thoracic pain (neither retrosternal nor oppressive), stabbing, well localized pain, no history of coronary heart disease, absence of general practitioner's concern, and pain reproducible by palpation. This last variable accounted for 2 points in the clinical prediction rule, the others for 1 point each; the total score ranged from 0 to 7 points. The area under the receiver operating characteristic (ROC) curve was 0.80 (95\% confidence interval $0.76-0.83$ ) in the derivation cohort (specificity: 89\%; sensitivity: 45\%; cut-off set at 6 points). Among all patients presenting CWS $(n=284), 71 \%(n=201)$ had a pain reproducible by palpation and $45 \%(n=127)$ were correctly diagnosed. For a subset $(n=43)$ of these correctly classified CWS patients, 65 additional investigations (30 electrocardiograms, 16 thoracic radiographies, 10 laboratory tests, eight specialist referrals, one thoracic computed tomography) had been performed to achieve diagnosis. False positives $(n=41)$ included three patients with stable angina ( $1.8 \%$ of all positives). External validation revealed the ROC curve to be 0.76 (95\% confidence interval $0.73-0.79$ ) with a sensitivity of $22 \%$ and a specificity of $93 \%$.

Conclusions: This CWS score offers a useful complement to the usual CWS exclusion diagnosing process. Indeed, for the 127 patients presenting CWS and correctly classified by our clinical prediction rule, 65 additional tests and exams could have been avoided. However, the reproduction of chest pain by palpation, the most important characteristic to diagnose CWS, is not pathognomonic.
\end{abstract}

Keywords: Chest pain, Primary care, Thoracic wall, Musculoskeletal system, Decision support techniques, Diagnosis

\section{Background}

When evaluating a patient with chest pain, the initial diagnostic step aims to rule out a life-threatening cause such as acute coronary syndrome or a pulmonary embolism [1]. However, the most common aetiology of chest pain in primary care practice is chest wall syndrome (CWS) [2], a benign source of chest pain

\footnotetext{
* Correspondence: alexandre@ronga.net

'Institute of General Medicine, University of Lausanne, Lausanne, Switzerland Full list of author information is available at the end of the article
}

localized to the anterior chest wall and caused by a musculoskeletal disorder [2,3]. Recent studies have shown that its incidence in primary care ranges from $20.4 \%$ to $46.6 \%[2,4-6]$.

CWS remains a diagnostic challenge [7]. Due to the absence of a consensus for diagnosing CWS, the diagnosis is usually obtained after the exclusion of other causes of chest pain, but this approach is time-consuming and requires important resources that could be directed elsewhere. Clinical signs related to CWS have been shown

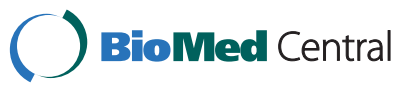


to be distinct from those of other more severe diagnoses [1], suggesting thata clinical prediction rule may help to identify patients with CWS. Although it is critical to exclude a life-threatening condition, reaching a diagnosis also seems to be very important for patients [8]. The need to develop non-invasive algorithms for primary care patients complaining of chest pain has been mentioned previously [9]. A literature review did not uncover a previously reported, validated clinical prediction rule for CWS [2,3,10-18], although a recent study described a four-point algorithm (localized muscle tension, stinging pain, pain reproducible by palpation and absence of cough) that can contribute to the diagnosis of CWS [10]. The aim of the present study was to develop and validate a clinical prediction rule for diagnosing CWS based on medical history and physical examination alone.

\section{Methods}

\section{Design overview}

We used data from the TOPIC (Thoracic Pain in Community) cohort, a multicentre cohort of primary care patients with chest pain, to develop a clinical prediction rule for CWS. We then analyzed data from a German study (the initial Marburg chest pain study, designed and conducted independently of the TOPIC cohort), a multicentre cohort of primary care patients with acute chest pain, to validate our rule. The original purpose of both studies was to investigate the characteristics of chest pain in primary care practice. Methods for both studies have been established previously and described (fully or partially) in various publications $[2,6,10,19-30]$. Later in the text, the TOPIC cohort will be referred as the "derivation cohort" and the German study as the "validation cohort".

\section{Setting and participants: derivation cohort}

General practitioners (GPs) in 58 independent medical offices and the medical residents of one university hospital outpatient department in Western Switzerland (counted as one additional practice) participated in the TOPIC study. All consecutive patients presenting with anterior chest pain (as a main or minor medical complaint) over a three-to-nine-week period (median length, five weeks) from March to May 2001 were included. Participating physicians had an average duration of experience in private practice of 12 years (range, 1-24 years). They received detailed information on the study and were trained to complete the forms during a meeting. The study protocol was approved by the Ethical Committee of the Canton of Vaud (Prot. 41/2000) [20].

\section{Setting and participants: validation cohort}

Between October 2005 and July 2006, all attending patients with anterior chest pain (aged 35 years and over; $\mathrm{n}=1249)$ were consecutively recruited to this study by 74 participating GPs in the state of Hesse, Germany. The recruitment period lasted 12 weeks for each practice. Patients were excluded when chest pain had lasted for one month or had already been noted by the primary care physician. The overall study protocol was approved by the Ethical Committee of the Faculty of Medicine, University of Marburg [6].

\section{Outcome and variables}

CWS is defined as a benign cause of chest pain localized to the anterior chest wall and caused by a musculoskeletal disorder [2,3]. CWS is coded in the International Classification of Disease (ICD 10 R07.4) as "Anterior chest-wall pain not otherwise specified," as well as in the International Classification of Primary Care (ICPC) under L04 as "Pain attributed to chest wall/pain attributed to musculoskeletal system" and under A11 as "Chest pain not otherwise specified" [31,32]. CWS includes fibromyalgia but excludes traumas, metastasis, and referred pain from the back. CWS encompasses various syndromes and clinical entities, such as costochondritis, costosternal syndrome, Tietze's syndrome, chondrocostal pain, slipping rib syndrome, intercostal pain, left chondrocostal syndrome, left pectoral syndrome, and sternal syndrome [2].

A literature review was performed for two purposes. First, we wished to determine whether any clinical prediction rules for CWS had been generated for primary care. Bösner et al. developed a simple score containing four determinants [10], but it has not been validated in an external cohort. Second, we wished to identify relevant variables used to describe CWS for collection from patient histories and physical examinations (Table 1 [2,3,10-18]). The following key words were used to search PubMed: "Chest Pain"[Mesh] AND ("Thoracic Wall"[Mesh] OR "Musculoskeletal System"[Mesh] OR "Musculoskeletal Diseases"[Mesh]) AND "Diagnosis" [Mesh]. In addition to the variables identified in the literature, those that appeared clinically relevant were selected for inclusion in this study.

\section{Data sources: derivation cohort}

Information was recorded regarding GP activity, age, and experience, as well as patient basic characteristics, key past history, pain characteristics, and associated symptoms. The first part of the case report form (CRF) included 70 questions on history and clinical examination of chest pain. With the exception of age, all variables were dichotomized. Information about additional medical tests, the suspected diagnosis, and treatment decision was also recorded [20]. Follow-up data were obtained during additional consultations three and 12 months after the initial contact. CRFs included 
Table 1 Variables indicating chest wall syndrome (ambiguous variables in bold)

\begin{tabular}{|c|c|c|}
\hline \multicolumn{3}{|l|}{ Medical history } \\
\hline \multirow[t]{5}{*}{ Thoracic pain described as } & Sharp/stinging & Trivial \\
\hline & Aching & Lasting more than 5 min \\
\hline & Not squeezing nor oppressive & Localized to one small area of the chest \\
\hline & Pressure-like & Left or median left part of the chest wall \\
\hline & Of varying intensity & Unilateral \\
\hline \multirow[t]{4}{*}{ Relieving factors } & Decrease movement & Nitroglycerine don't relieve \\
\hline & Cessation of movement & Rest don't relieve \\
\hline & Change in position & Quiet breathing \\
\hline & Physical activity & \\
\hline \multirow[t]{8}{*}{ Associated/triggering factors } & Exertion & Physical activities that stress the upper body \\
\hline & Not exercise-induced & No consistency according to exercise \\
\hline & Certain activities & Unaccustomed physical activity \\
\hline & At rest & Trunk movement/movement \\
\hline & Coughing & Certain position \\
\hline & Absence of cough & Antecedent illness with coughing \\
\hline & Repeated minor trauma & Deep breathing \\
\hline & History of rhumatoid arthritis & Psychic stress \\
\hline \multicolumn{3}{|l|}{ Physical examination } \\
\hline \multirow[t]{3}{*}{ Palpation } & Pain is reproducible & Chest wall tenderness \\
\hline & Pain may not be reproducible & Localized muscle tension \\
\hline & Paraspinal tenderness & \\
\hline Tests & Horizontal flexion of arm & Spinal motion palpation restriction \\
\hline
\end{tabular}

information on further examinations and laboratory assays, referrals to specialists, admissions to emergency wards, hospitalizations, and health events during the follow-up period. The initial suspected diagnosis was confirmed or modified during follow-up; we used the GP's final diagnosis at 12 months as the reference diagnosis. When it was not possible to confirm the diagnosis, or if the diagnosis at 12 months was missing, the patient was contacted for further information through his GP. If the patient could not be contacted, the diagnosis at three months was retained. This method is not believed to be perfect, but is the best acceptable solution for studies in family practice settings [33]. The GP's diagnosis was classified by the research team as CWS if it matched anything under this umbrella term as defined in the ICPC (see above, in section on outcome and variables).

\section{Data sources: validation cohort}

As described previously [6], GPs took a standardized history and performed a physical examination according to a CRF. They also recorded their preliminary diagnoses, investigations, and management related to the patients' chest pains. Patients were contacted by phone six weeks and six months after the index consultation. Study assistants blinded to the clinical data already recorded inquired about the course of the patients' chest pain as well as treatments including hospitalization and drugs. Discharge letters from specialists and hospitals were requested from GPs.

\section{Protection against bias: derivation cohort}

All completed forms were sent to the study coordination centre. A set of predefined criteria was used for data entry checks, and the GPs were contacted to resolve inconsistencies or to complete missing data. Double data entry was used to identify transcription errors. Data cleaning and validation was performed by a group of physicians experienced in research. When the diagnosis reported by the GP was not consistent throughout the follow-up year, the final diagnosis for chest pain was discussed and approved by a group of clinicians who were not aware of the aim of this study. Quality control of the reported diagnosis was done using patients up to date medical records at the GP's office for a random ten percent sample of the included patients. No inconsistencies were identified.

\section{Protection against bias: validation cohort}

As described previously [6], participating practices were recruited from a network of research practices associated with the University of Marburg Department of General Practice. The importance of recruiting every 
patient with chest pain irrespective of the presumed likelihood of ischemic heart disease was emphasized to the participating GPs. Practices were visited at 4-week intervals to check CRFs, recruitment logs, and compliance with study procedures. Random audits of the routine documentation of participating practices were implemented to identify cases of chest pain not included in the study. After six months, a reference panel consisting of one cardiologist, one GP, and one member of the research staff at the Department of Family Medicine reviewed the baseline and follow-up data of each patient. Analyzing all the information gathered during the follow-up period (results of further investigations, letters from specialists, hospital discharge reports, etc.), the panel decided on the most likely medical condition responsible for each patient's chest pain at baseline.

\section{Statistical analysis}

Using data from the derivation cohort alone, bivariate logistic regression analysis was performed to detect variables associated with CWS. Odds ratios (ORs) $\geq 2.0$ were retained as potentially relevant for the multivariate analysis. To prevent overfitting related to colinearity, we

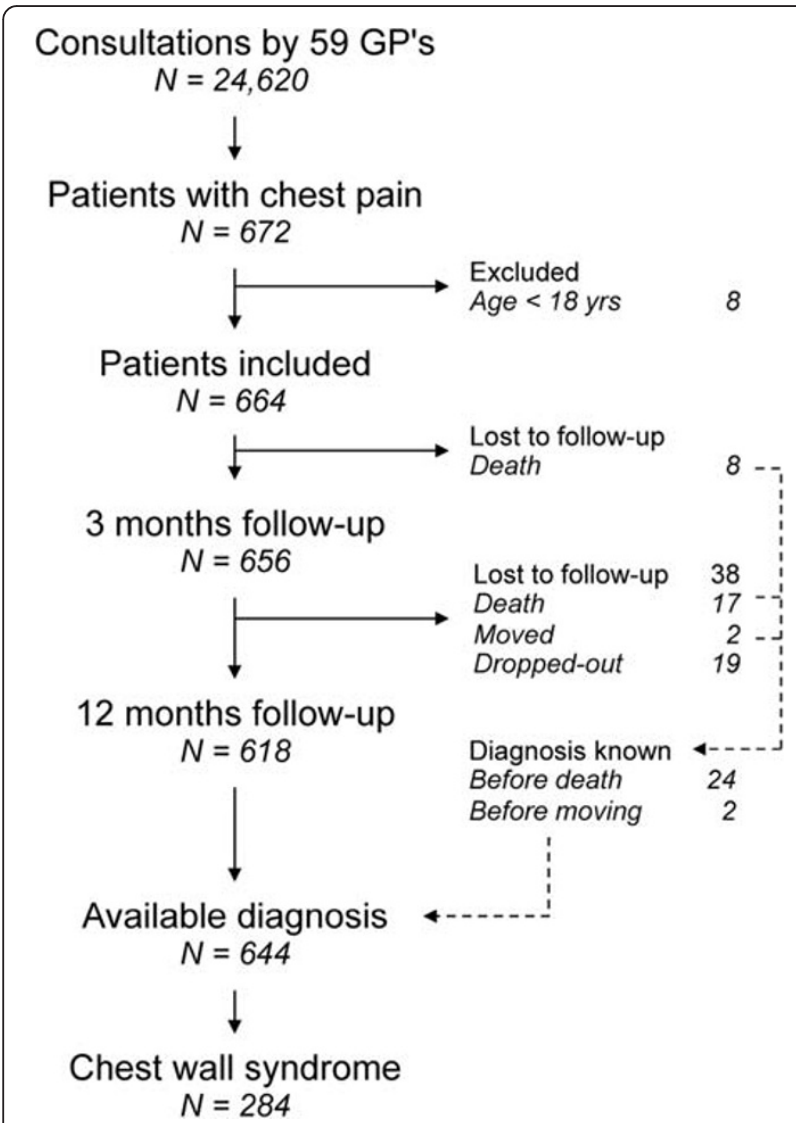

Figure 1 Flow chart of derivation cohort: patient recruitment and follow-up data. GPS = general practitioners. explored the advantages of combining similar factors. For example, the variables "well localized pain (medical history)" and "well localized pain (physical examination)" were combined to create the variable "well localized pain (medical history and/or physical examination)." Variables were retained if their combination significantly improved the multivariate model compared to the use of either factor alone in the model (P-value of likelihood ratio test between models $<0.05$ ). According to the regression coefficients in the multivariate analysis, weights (points) were attributed to each factor in order to build a score. The area under the receiver operating characteristic (ROC) curve was measured as an indicator of the discriminatory power of the score. We arbitrarily set the cut-off for specificity at $\geq 85 \%$. Other researchers have used this cut-off for specificity [34].

The retained score was then applied to the validation cohort for external validation. Clinical signs that were not reported by the physician were considered absent by default. A second analysis was performed by multiple imputation for missing values of the key variable (pain reproducible by palpation). In the validation cohort, the best proxy for "pain well localized" was "localized muscle tension". The extent of pain from other tissues could not be taken into account. Area under the ROC curve, sensitivity, and specificity were calculated in both cohorts. All analyses were performed with StataCorp. 2009 Statistical Software (release 11.0, StataCorp, College Station, Texas, USA).

\section{Results}

\section{Study population (derivation cohort)}

A total of 664 patients with chest pain, aged 18 years and over, were included in the derivation cohort (22 patients were included and followed by the University Hospital Outpatient Department). Of these, 618 (93\%) completed a 12-month follow-up with an available diagnosis. For the 46 cases with no formal diagnosis at 12

Table 2 Number, age and sex of derivation and validation cohorts: patients with CWS and whole study population at baseline

\begin{tabular}{lllc}
\hline Study & Baseline characteristics & $\begin{array}{l}\text { CWS } \\
\text { patients }\end{array}$ & $\begin{array}{l}\text { Study } \\
\text { population }\end{array}$ \\
\hline Derivation cohort & Number of patients (\%) & $284(44.1)$ & $644(100.0)$ \\
& Mean age (range), years & $50.5(18-90)$ & $55.4(18-95)$ \\
& $\begin{array}{l}\text { Sex: male patients, } \\
\text { number (\%) }\end{array}$ & $136(47.9)$ & $307(47.7)$ \\
\hline Validation cohort & Number of patients (\%) & $565(46.6)$ & $1212(100.0)$ \\
& Mean age (range), years & $58(35-90)$ & $59(35-93)$ \\
& $\begin{array}{l}\text { Sex: male patients, } \\
\text { number (\%) }\end{array}$ & $235(41.6)$ & $534(44.1)$ \\
& & \\
\hline
\end{tabular}

CWS chest wall syndrome. 
months, 25 died, two moved, and 19 had no diagnosis. However, diagnoses were available for 26 of these patients, with the diagnosis known before death or

Table 3 Odds of having chest wall syndrome (CWS) for all potential predictors and availability of each variable for external validation. Final variables retained for the clinical prediction rule are given in bold

\begin{tabular}{|c|c|c|c|}
\hline Simple variables & $\begin{array}{l}\text { OR CWS } \\
\text { vs. others } \\
(95 \% \mathrm{Cl})\end{array}$ & P-value & $\begin{array}{c}\text { Available for } \\
\text { external } \\
\text { validation }\end{array}$ \\
\hline $\begin{array}{l}\text { Trivial (history and } \\
\text { physical examination) }\end{array}$ & $9.11(5.52-15.03)$ & $<0.001$ & No \\
\hline $\begin{array}{l}\text { Pain reproducible } \\
\text { by palpation }\end{array}$ & $6.47(4.58-9.15)$ & $<0.001$ & Yes \\
\hline $\begin{array}{l}\text { No history of coronary } \\
\text { heart disease }\end{array}$ & $5.12(2.88-9.12)$ & $<0.001$ & Yes \\
\hline Pain not retrosternal & $5.08(2.94-8.78)$ & $<0.001$ & Yes \\
\hline $\begin{array}{l}\text { Absence of general } \\
\text { practitioner's concern }\end{array}$ & $4.96(2.79-8.84)$ & $<0.001$ & Yes \\
\hline Pain well localized (history) & $2.65(1.91-3.67)$ & $<0.001$ & Yes \\
\hline Pain superficial & $2.48(1.72-3.56)$ & $<0.001$ & No \\
\hline $\begin{array}{l}\text { Pain well localized } \\
\text { (physical examination) }\end{array}$ & $2.46(1.78-3.39)$ & $<0.001$ & Yes \\
\hline Pain not oppressive & $2.37(1.69-3.31)$ & $<0.001$ & Yes \\
\hline Pain related to position & $2.13(1.48-3.06)$ & $<0.001$ & No \\
\hline Stabbing pain & $2.11(1.38-3.24)$ & 0.001 & Yes \\
\hline Pain related to movement & $2.06(1.42-3.01)$ & $<0.001$ & Yes \\
\hline Pain is not burning & $1.62(0.94-2.77)$ & 0.081 & Yes \\
\hline Pain is not spread & $1.52(1.03-2.25)$ & 0.037 & No \\
\hline Pain is not deep & $1.30(0.95-1.78)$ & 0.100 & No \\
\hline Pain related to breathing & $1.19(0.83-1.71)$ & 0.344 & Yes \\
\hline Absence of stressful stimulus & $1.15(0.72-1.82)$ & 0.560 & No \\
\hline Intermittent pain & $0.95(0.69-1.29)$ & 0.723 & Yes \\
\hline Absence of patient's concern & $0.92(0.67-1.26)$ & 0.613 & Yes \\
\hline Radiating pain & $0.78(0.51-1.20)$ & 0.255 & Yes \\
\hline $\begin{array}{l}\text { Pain is accompanied } \\
\text { by cough }\end{array}$ & $0.83(0.56-1.24)$ & 0.361 & Yes \\
\hline Pain related to cough & $0.57(0.37-0.89)$ & 0.013 & No \\
\hline \multicolumn{4}{|l|}{ Combined variables } \\
\hline $\begin{array}{l}\text { Pain neither retrosternal } \\
\text { nor oppressive }\end{array}$ & $3.11(2.24-4.33)$ & $<0.001$ & Yes \\
\hline $\begin{array}{l}\text { Pain well localized } \\
\text { (history and/or } \\
\text { physical examination) }\end{array}$ & $3.07(2.17-4.35)$ & $<0.001$ & Yes \\
\hline $\begin{array}{l}\text { Pain related to mechanical } \\
\text { factors (position } \\
\text { and/or movement) }\end{array}$ & $2.56(1.85-3.56)$ & $<0.001$ & No \\
\hline $\begin{array}{l}\text { Pain is accompanied by } \\
\text { digestive symptoms } \$\end{array}$ & $0.54(0.35-0.85)$ & 0.01 & No \\
\hline
\end{tabular}

retained at the 3-month follow-up. Therefore, the population analyzed in this study consisted of 644 patients (Figure 1), 47.7\% male, with mean age 55.4 years (range 18-95 years). CWS was diagnosed in 284 cases (Table 2). Chest pain was reproducible by palpation for $299 / 644$ (46.4\%) patients of the derivation cohort and for 201/284 (70.1\%) of the CWS patients.

\section{Building the clinical prediction rule}

Comparing CWS patients with the remainder of the cohort, bivariate analyses identified 12 simple variables and three combined variables significantly associated with CWS (OR > 2.0) (Table 3). Only variables available for external validation (Table 3) were included in the regression model. A backward-stepwise method implemented to remove less-significant variables one by one resulted in the retention of six significant variables that were used to build the clinical prediction rule. The P-values, regression coefficients, and point attributions of these variables are shown in Table 4. The regression coefficients, which ranged from 0.5 to 1.6 , were used to explore an accurate score model (points attributed for each variable ranging from 1 to 3 , total score 10 points), but the accurate score model exhibited the same performance as the simplified model presented here.

Given its stronger regression coefficient (1.64) the variable "pain reproducible with palpation" accounted for two points and the other variables for one point, for a total score ranging from 0 to 7 points. The area under the ROC curve was 0.8 (95\% confidence interval 0.76 0.83 ; Figure 2). We set the cut-off point at 6 points, corresponding to a specificity of $88.6 \%$. Application of this rule to the derivation cohort led to the correct

Table 4 Multivariate analysis (pseudo $R^{2}: 0.2244$ ): $P$-values, regression coefficients and number of points attributed to build the chest wall syndrome (CWS) clinical prediction rule

\begin{tabular}{lccc}
\hline Variable & $\begin{array}{c}\text { P-value } \\
\text { Regression } \\
\text { coefficient }\end{array}$ & $\begin{array}{c}\text { Number of } \\
\text { points attributed } \\
\text { for rule }\end{array}$ \\
\hline Pain reproducible by palpation & $<0.001$ & 1.64 & 2 \\
$\begin{array}{l}\text { No history of coronary } \\
\text { heart disease }\end{array}$ & $<0.001$ & 1.25 & 1 \\
$\begin{array}{l}\text { Absence of general } \\
\text { practitioner's concern }\end{array}$ & 0.001 & 1.13 & 1 \\
$\begin{array}{l}\text { Pain neither retrosternal } \\
\text { nor oppressive }\end{array}$ & 0.017 & 0.48 & 1 \\
$\begin{array}{l}\text { Pain well localized (history } \\
\text { and/or physical examination) }\end{array}$ & 0.002 & 0.64 & 1 \\
$\begin{array}{l}\text { Stabbing pain } \\
\begin{array}{l}\text { Total number of points } \\
\text { attributable }\end{array}\end{array}$ & 0.041 & 0.50 & 1 \\
\hline
\end{tabular}

CWS chest wall syndrome. 


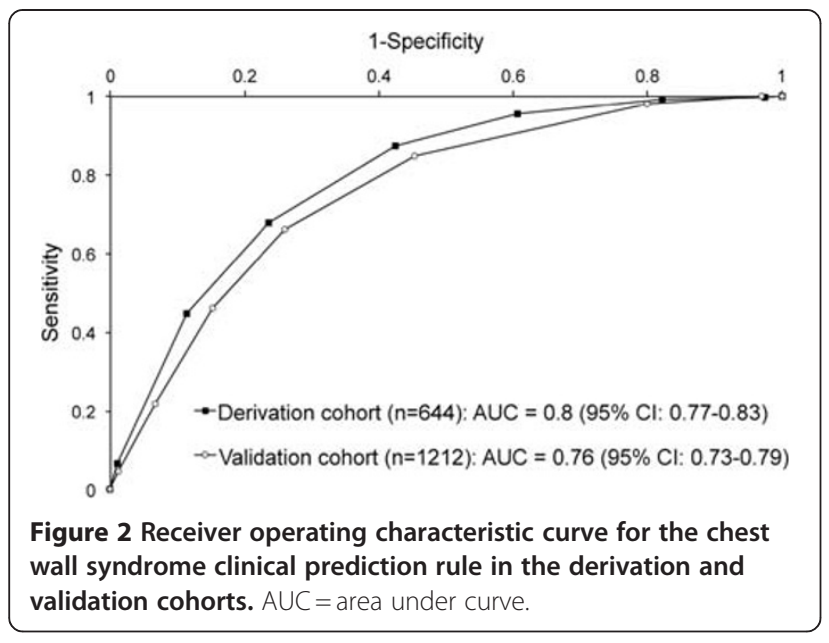

classification of 127/284 (44.7\%) patients with CWS. For 43 of these correctly classified CWS patients, 65 additional exams (30 electrocardiograms, 16 thoracic radiographies, 10 laboratory tests, eight specialist referrals, and one thoracic computed tomography) had been prescribed to reach the diagnosis. Figure 3 shows the observed prevalence of CWS for each score value. There were 41 false-positive patients, including three patients with stable angina ( $1.8 \%$ of all positives). Classification of each diagnostic subgroup by the CWS clinical prediction rule is detailed in Table 5.

\section{External validity}

We accessed and used the Marburg database for external validation [6]. Diagnostic classification was possible for 1212 patients, including 565 diagnoses of CWS (46.6\%). When applied to the validation cohort, the clinical prediction rule for CWS had an area under the ROC curve of 0.76 (95\% confidence interval 0.73-0.79), 93.4\% specificity, and $22.0 \%$ sensitivity (Figure 2 ), corresponding to a positive likelihood ratio of 3.3. Of all CWS patients, 124 were correctly classified (22\% of total; Figure 3). There were 43 false positives, including three patients with stable angina ( $1.8 \%$ of all positives). No significant change was found after multiple imputation for missing values of the key variable "pain reproducible by palpation".

\section{Discussion}

We developed a clinical prediction rule for the diagnosis of CWS. The score ranges from 0 to 7 points, and the cut-off was set at 6 points to obtain specificity $>85 \%$. The rule contains the following six variables: thoracic pain (neither retrosternal nor oppressive), stabbing pain, well localized pain, no history of coronary heart disease, absence of GP concern, and pain reproducible by palpation ( 2 points). In the derivation cohort, the area under the curve was 0.8 and the specificity was $88.6 \%$ (319/ $360)$. The external validation showed $93 \%(604 / 647)$ specificity with an area under the curve of 0.76 (95\% confidence interval 0.73-0.79). In addition, we observed that the reproduction of chest pain by palpation is not pathognomonic of CWS.

The strengths of our study include the large numbers of participating GPs and patients, allowing us to assume that our sample is fairly representative. We implemented a pragmatic strategy by consecutively including patients through their GP practice. We achieved an excellent follow-up at one year (96\%), and more than half of the patients lost to follow-up had an available diagnosis. A

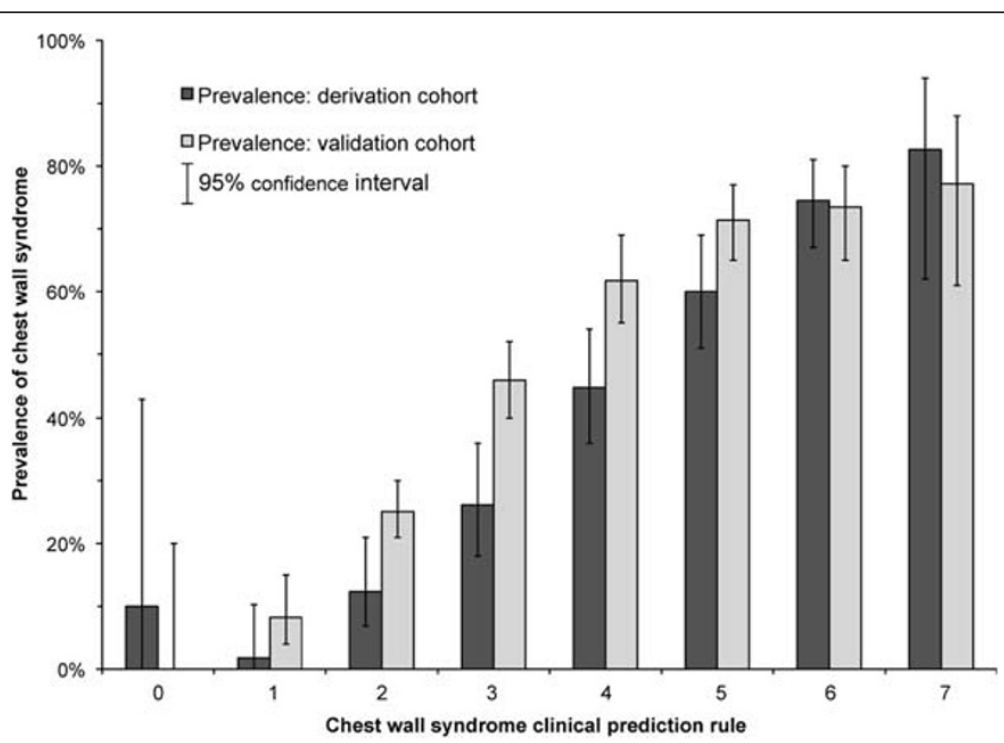

Figure 3 Observed prevalence of chest wall syndrome (CWS) in the derivation and validation cohorts for each clinical prediction rule value. 
Table 5 Classification of other diagnosis by the chest wall syndrome (CWS) clinical prediction rule

\begin{tabular}{|c|c|c|}
\hline \multirow[t]{2}{*}{ Diagnostic groups } & \multicolumn{2}{|c|}{ Classification by the CWS rule } \\
\hline & $\begin{array}{c}\text { False positive } \\
\mathrm{N}=41\end{array}$ & $\begin{array}{c}\text { True negative } \\
\mathrm{N}=476\end{array}$ \\
\hline Musculoskeletal (non-CWS) & 18 & 23 \\
\hline Traumatic & 14 & 10 \\
\hline Parietal metastasis & 0 & 7 \\
\hline Post-thoracotomy & 2 & 4 \\
\hline Arthritis/arthrosis & 2 & 2 \\
\hline Cardiovascular & 3 & 105 \\
\hline Stable angina & 3 & 72 \\
\hline Unstable angina & 0 & 6 \\
\hline Myocardial infarction & 0 & 4 \\
\hline Pulmonary embolism & 0 & 2 \\
\hline Arrythmia & 0 & 10 \\
\hline Valvular disease & 0 & 2 \\
\hline Cardiac insufficiency & 0 & 3 \\
\hline Cardiomyopathy & 0 & 1 \\
\hline Acute hypertension & 0 & 5 \\
\hline Psychogenic & 10 & 66 \\
\hline Anxious & 6 & 48 \\
\hline Somatisation & 4 & 18 \\
\hline Pulmonary & 2 & 66 \\
\hline Infectious & 2 & 53 \\
\hline Non-infectious & 0 & 13 \\
\hline Digestive & 3 & 52 \\
\hline Peptic affections & 1 & 46 \\
\hline Non-peptic affections & 2 & 6 \\
\hline Miscellaneous & 5 & 7 \\
\hline Mastitis/mastalgia & 4 & 1 \\
\hline Cutaneous abcess & 0 & 1 \\
\hline Herpes zoster & 1 & 1 \\
\hline Sarcoidosis & 0 & 2 \\
\hline Chest wall keloid & 0 & 1 \\
\hline Acute pyelonephritis & 0 & 1 \\
\hline
\end{tabular}

key feature of our study was our external validation, which allowed us to confirm our results. However, our study suffers several limitations. First, delayed diagnosis was used as a reference in the absence of a panel of experts or an independent diagnostic process. It was not possible to perform additional tests systematically in all patients. Second, there is currently no consensus about the determinants or the designations of CWS in the literature. Third, there was no specific calibration for the variable "pain reproducible with palpation," which may have induced differences in individual interpretations. Fourth, some variables were not available for external validation, and although they were relevant to the bivariate analyses, they could not be included in the development of the clinical prediction rule. Fifth, the two cohorts showed design differences, what could weaken their comparison. Only patients with acute chest pain were included in the validation cohort; in addition, the reference diagnosis was made by means of a telephoneinterview of the patient in the validation cohort. The TOPIC study was not originally designed for the development of a clinical prediction rule for CWS; if it had been, then other diagnostic criteria may have been explored.

Our requirement that the prediction rule be highly specific leads, unsurprisingly, to a relatively low rate of patients with CWS correctly classified in the derivation cohort $(127 / 284=45 \%)$. A lower rate $(124 / 565=22 \%)$ in the validation cohort can be partly explained by design differences and semantic limits. In the derivation cohort, the 41 false positives were not life-threatening cases; most of these cases were easily identifiable and were associated with a plausible pathophysiological mechanism for chest pain such as trauma or thoracotomy. Interestingly, parietal metastases were not classified as false positives. However, our score misclassified three patients (1.8\% of all positives cases) with stable angina as CWS. For these three patients, the GPs had noted symptoms and signs for CWS as well as for cardiovascular disease, and we therefore suspect the co-existence of both diagnoses for these three patients. Therefore, patients with a positive CWS clinical prediction rule in the presence of other signs of chest pain must be carefully examined and monitored for the final diagnosis and evolution of chest pain.

In the literature, we found no consensus about the classification or the determinants of CWS, and the pertinence of some variables is ambiguous. This lack of clarity had already been identified [2,3,35,36]. Our study provides a clear definition of CWS as well as a diagnostic tool. Although another score has been previously described [10], we have presented a validated tool. Another important difference between these two works is the variable "absence of cough;" whereas this variable is not relevant in our cohort, it was included in the fourpoint score developed by Bösner et al. [10]. However, since this variable is interpreted in various ways in the literature, we believe that it is not optimal in the diagnosis of CWS. Finally, the reproducibility of chest pain by palpation is addressed repeatedly in the literature. According to our clinical prediction rule, this variableis necessary for the diagnosis of CWS. Although this reproducibility was previously thought to be the strongest evidence of CWS [4], more recent work has demonstrated that it is not pathognomonic of CWS $[3,37,38]$, a finding we have confirmed. 
Universal consensus requiresthe exclusion of a potentially life-threatening cause of chest pain in the emergency department and in primary care practice [1,39], and patients with CWS are referred to their GPs for further investigation. There is a low prevalence of patients presenting CWS in the emergency department [5], and this disease is not followed up there. However, in addition to an emergency department triage approach, GPs must establish the diagnosis, and will treat and follow their patients regardless of the final diagnosis. Our clinical prediction rule will aid this process. Further studies may be necessary to verify the effectiveness of our rule and to improve the management of CWS.

\section{Conclusion}

In conclusion, CWS is a frequent diagnosis in primary care that is well known by general practitioners but has been insufficiently studied in the literature. Our proposed clinical prediction rule constitutes a tool that can be used in addition to the usual process of diagnosing CWS by elimination. Moreover, because its high specificity, a high positive score may help clinicians to avoid ordering additional tests. For instance, using this tool, 65additional exams for 127 patients could have been avoided in the derivation cohort. We propose that our clinical prediction rule should be included in the clinical diagnostic reasoning of physicians encountering a patient with chest pain in primary care, keeping in mind that it does not exclude the presence of concomitant diagnoses.

\section{Abbreviations}

AUC: Area under the curve; CRF: Case report form; CWS: Chest wall syndrome; GP: General practitioner; OR: Odd ratio; $R^{2}$ : Coefficient of determination; ROC: Receiver operating characteristic; $95 \% \mathrm{Cl}$ : 95\% confidence interval.

\section{Competing interests}

The authors declare that they have no competing interests.

\section{Authors' contributions}

FV and LH conceived the study, participated in patient inclusion, were the principle investigators, and critically revised the manuscript. BB and BF participated in the design of the study and critically revised the manuscript. PV designed the statistical analysis, and participated in drafting the manuscript. AR performed the statistical analysis and wrote the manuscript. TB participated in patient inclusion and critically revised the manuscript. JH, NDB and SB participated in the statistical analyses of the external validation and critically revised the manuscript. All authors accepted the manuscript after reading.

\section{Acknowledgements}

We are indebted to the Swiss Academy of Medical Sciences for a grant that supported the study (RMMA 6/2000). We thank Françoise Secretan for her valuable work as the coordinating research nurse and the following colleagues (GPs) for counseling and clinical contribution: Marc Abdelmoula, James Alexander, Jean-Marc Bidaux, Michel Bidlingmeyer, Thomas Bischoff, Corine Bonard, Marc Bonard, Jean-Luc Bourban, Jean-Paul Bussien, Christophe Chapuis, François Chuard, Georges Conne, Christian Cuendet, Michel Daflon, Marco Danese, Marysede Vevey, Janine Dumas, Charles Dvorak, Michel Eddé, Jürg Eidenbenz, Philippe Erard, Véronique Gerber Genier, Willy Gilgien, Bernard Giorgis, Michel Graff, Lilli Herzig, Thierry Horn, Pierre-Yves Jaquet, Sébastien Jotterand, Michel Junod, Laurent Kaufmann,
Abel Lanaspa, Raymond Larpin, Claude Matthey, Alain Michaud, Gianni Minghelli, Rafael Morales, Nicole Muhlemann, Andrea Müller, François Murisier, Marie-Amélie Pernet, Raymond Pernet, François Pilet, Olivier Pyroth, Luc Robyn, Olivier Rubli, Pierre-Alain Schmied, Alain Schwob, Jacques Sommer, Jean-Paul Studer, Etienne Urfer, Pascal Valotton, François Verdon, Jean-Pierre Voegeli, Yves-Marie Wasem, Marc Wenner, Pierre Widmer, Claude Yersin. We also thank all the physicians who collected data for the University of Marburg.

\section{Author details}

'Institute of General Medicine, University of Lausanne, Lausanne, Switzerland. ${ }^{2}$ Department of Community Medicine and Primary care, University of Geneva, Geneva, Switzerland. ${ }^{3}$ Department of General Practice/Family Medicine, University of Marburg, 35032 Marburg, Germany. ${ }^{4}$ Institute of Social and Preventive Medicine, Lausanne University Hospital, Lausanne, Switzerland. ${ }^{5}$ Department of Ambulatory Care and Community Medicine, University of Lausanne, Lausanne, Switzerland.

Received: 19 March 2012 Accepted: 16 July 2012

Published: 6 August 2012

\section{References}

1. Yelland M, Cayley WE Jr, Vach W: An algorithm for the diagnosis and management of chest pain in primary care. Med Clin North Am 2010, 94(2):349-374

2. Verdon F, Burnand B, Herzig L, Junod M, Pecoud A, Favrat B: Chest wall syndrome among primary care patients: a cohort study. BMC Fam Pract 2007, 8:51.

3. Epstein SE, Gerber LH, Borer JS: Chest wall syndrome. A common cause of unexplained cardiac pain. JAMA 1979, 241(26):2793-2797.

4. Klinkman MS, Stevens D, Gorenflo DW: Episodes of care for chest pain: a preliminary report from MIRNET. Michigan Research Network. J Fam Pract 1994, 38(4):345-352.

5. Buntinx F, Knockaert D, Bruyninckx R, de Blaey N, Aerts M, Knottnerus JA, Delooz H: Chest pain in general practice or in the hospital emergency department: is it the same? Fam Pract 2001, 18(6):586-589.

6. Bosner S, Becker A, Haasenritter J, Abu Hani M, Keller H, Sonnichsen AC, Karatolios K, Schaefer JR, Seitz G, Baum E, et al: Chest pain in primary care: epidemiology and pre-work-up probabilities. Eur J Gen Pract 2009, 15(3):141-146

7. Schwartz L, Bourassa MG: Evaluation of patients with chest pain and normal coronary angiograms. Arch Intern Med 2001, 161(15):1825-1833.

8. Nijher G, Weinman J, Bass C, Chambers J: Chest pain in people with normal coronary anatomy. BMJ 2001, 323(7325):1319-1320.

9. Coulshed DS, Eslick GD, Talley NJ: Non-cardiac chest pain. Patients need diagnoses. BMJ 2002, 324(7342):915.

10. Bosner S, Becker A, Hani MA, Keller H, Sonnichsen AC, Karatolios K, Schaefer $J R$, Haasenritter J, Baum E, Donner-Banzhoff N: Chest wall syndrome in primary care patients with chest pain: presentation, associated features and diagnosis. Fam Pract 2010, 27(4):363-369.

11. Proulx AM, Zryd TW: Costochondritis: diagnosis and treatment. Am Fam Physician 2009, 80(6):617-620.

12. Singh AM, McGregor RS: Differential diagnosis of chest symptoms in the athlete. Clin Rev Allergy Immunol 2005, 29(2):87-96.

13. Christensen HW, Vach W, Gichangi A, Manniche C, Haghfelt T, HoilundCarlsen PF: Cervicothoracic angina identified by case history and palpation findings in patients with stable angina pectoris. J Manip Physiol Ther 2005, 28(5):303-311.

14. Jawad E, Arora R: Chronic stable angina pectoris. Disease-a-month: DM 2008, 54(9):671-689.

15. Rovetta G, Sessarego P, Monteforte P: Stretching exercises for costochondritis pain. G Ital Med Lav Ergon 2009, 31(2):169-171.

16. Cayley WE Jr: Diagnosing the cause of chest pain. Am Fam Physician 2005, 72(10):2012-2021.

17. Cooke RA, Smeeton N, Chambers JB: Comparative study of chest pain characteristics in patients with normal and abnormal coronary angiograms. Heart 1997, 78(2):142-146.

18. Wise CM, Semble EL, Dalton CB: Musculoskeletal chest wall syndromes in patients with noncardiac chest pain: a study of 100 patients. Arch Phys Med Rehabil 1992, 73(2):147-149. 
19. Verdon F, Herzig L, Burnand B, Bischoff T, Pecoud A, Junod M, Muhlemann N, Favrat B, Gmirg: Chest pain in daily practice: occurrence, causes and management. Swiss Med Wkly 2008, 138(23-24):340-347.

20. Gencer B, Vaucher P, Herzig L, Verdon F, Ruffieux C, Bosner S, Burnand B, Bischoff T, Donner-Banzhoff N, Favrat B: Ruling out coronary heart disease in primary care patients with chest pain: a clinical prediction score. $B M C$ Med 2010, 8:9.

21. Verdon F, Junod M, Herzig L, Vaucher P, Burnand B, Bischoff T, Pecoud A Favrat B: Predictive ability of an early diagnostic guess in patients presenting with chest pain; a longitudinal descriptive study. BMC Fam Pract 2010, 11:14.

22. Bosner S, Haasenritter J, Becker A, Hani MA, Keller H, Sonnichsen AC, Karatolios K, Schaefer JR, Baum E, Donner-Banzhoff N: Heartburn or angina? Differentiating gastrointestinal disease in primary care patients presenting with chest pain: a cross sectional diagnostic study. Int Arch Med 2009, 2:40.

23. Bosner S, Haasenritter J, Hani MA, Keller H, Sonnichsen AC, Karatolios K, Schaefer JR, Baum E, Donner-Banzhoff N: Gender differences in presentation and diagnosis of chest pain in primary care. BMC Fam Pract 2009, 10:79.

24. Glombiewski JA, Rief W, Bosner S, Keller H, Martin A, Donner-Banzhoff N: The course of nonspecific chest pain in primary care: symptom persistence and health care usage. Arch Intern Med 2010, 170(3):251-255.

25. Bosner S, Becker A, Abu Hani M, Keller H, Sonnichsen AC, Haasenritter J, Karatolios K, Schaefer JR, Baum E, Donner-Banzhoff N: Accuracy of symptoms and signs for coronary heart disease assessed in primary care. Br J Gen Pract 2010, 60(575):e246-e257.

26. Bosner S, Haasenritter J, Abu Hani M, Keller H, Sonnichsen AC, Karatolios K, Schaefer JR, Baum E, Donner-Banzhoff N: Accuracy of general practitioners' assessment of chest pain patients for coronary heart disease in primary care: cross-sectional study with follow-up. Croat Med J 2010, 51(3):243-249.

27. Bosner S, Haasenritter J, Becker A, Karatolios K, Vaucher P, Gencer B, Herzig L, Heinzel-Gutenbrunner M, Schaefer JR, Abu Hani M, et al: Ruling out coronary artery disease in primary care: development and validation of a simple prediction rule. CMAJ 2010, 182(12):1295-1300.

28. Bosner S, Haasenritter J, Hani MA, Keller H, Sonnichsen AC, Karatolios K, Schaefer JR, Baum E, Donner-Banzhoff N: Gender bias revisited: new insights on the differential management of chest pain. BMC Fam Pract 2011, 12:45.

29. Bosner S, Haasenritter J, Keller H, Abu Hani M, Sonnichsen AC, Baum E, Donner-Banzhoff $\mathrm{N}$ : The diagnosis of coronary heart disease in a low-prevalence setting: follow-up data from patients whose CHD was misdiagnosed by their family doctors. Deutsches Arzteblatt international 2011, 108(26):445-451.

30. Hirsch O, Bosner S, Hullermeier E, Senge R, Dembczynski K, Donner-Banzhoff $\mathrm{N}$ : Multivariate modeling to identify patterns in clinical data: the example of chest pain. BMC Med Res Methodol 2011, 11:155.

31. Organization WH: International Classification of Diseases. 10th Revision (ICD-10), version 2010.

32. World Organization of National Colleges AaAAoGPFPWiccW: International Classification of Primary Care. Second edition. 2005. ICPC-2e-v.3.0.

33. Knottnerus J, Butinx F: The Evidence Base of Clinical Diagnosis: Theory and Methods of Diagnostic Research, BMJ Books. London: Blackwell Publishing; 2009.

34. Cleland JA, Childs JD, Fritz JM, Whitman JM, Eberhart SL: Development of a clinical prediction rule for guiding treatment of a subgroup of patients with neck pain: use of thoracic spine manipulation, exercise, and patient education. Phys Ther 2007, 87(1):9-23.

35. Fam AG, Smythe HA: Musculoskeletal chest wall pain. CMAJ 1985, 133(5):379-389.

36. Fred HL: Atypical chest pain: a typical humpty dumpty coinage. Tex Heart Inst J 2009, 36(5):373-374.

37. Ho M, Walker S, McGarry F, Pringle S, Pullar T: Chest wall tenderness is unhelpful in the diagnosis of recurrent chest pain. QJM 2001, 94(5):267-270

38. Le Gal G, Testuz A, Righini M, Bounameaux H, Perrier A: Reproduction of chest pain by palpation: diagnostic accuracy in suspected pulmonary embolism. BMJ 2005, 330(7489):452-453.
39. Goyal N, Stant J, Esposito F, Piri G, Collins M, Sayan O, Neuberg G, Miller L, Moses JW, Stone GW, et al: Updating the chest pain algorithm: incorporating new evidence. Crit Pathw Cardiol 2008, 7(4):211-222.

doi:10.1186/1471-2296-13-74

Cite this article as: Ronga et al: Development and validation of a clinical prediction rule for chest wall syndrome in primary care. BMC Family Practice 2012 13:74.

\section{Submit your next manuscript to BioMed Central and take full advantage of:}

- Convenient online submission

- Thorough peer review

- No space constraints or color figure charges

- Immediate publication on acceptance

- Inclusion in PubMed, CAS, Scopus and Google Scholar

- Research which is freely available for redistribution 